\title{
Spontaneous Resolution of Acute Subdural Hematoma with a Good Clinical Outcome: A Case Report
}

\author{
In Kyung Lee, Sang Woo Song \\ Department of Neurosurgery, Konkuk University Medical Center, Konkuk University School of Medicine, Seoul, \\ Republic of Korea
}

Corresponding author:

Sang Woo Song

Department of Neurosurgery, Konkuk University

Medical Center, Konkuk University School of

Medicine, 120-1, Neungdong-ro, Gwangjin-gu,

Seoul 05030, Republic of Korea

Tel: $+82-2-2030-7357$

Fax: $+82-2-2030-7729$

E-mail: 20120168@kuh.ac.kr

Received: August 21, 2019

Revised: August 25, 2019

Accepted: August 26, 2019

\begin{abstract}
Acute subdural hematoma (ASDH) usually occurs with severe traumatic head injury, which could result in neurologic deteriorations and/or intracranial hypertension, requiring emergency decompression surgery. Even after vigorous medical treatment, ASDH with poor neurologic status and severe midline shift with brain herniation could bring a serious socioeconomic loss to patients and their families, and death is generally expected without surgical intervention. Here, we report a case of a 74-year-old man with ASDH who spontaneously disappeared under conservative treatment and discuss the possible mechanisms with a literature review.
\end{abstract}

Key Words: Brain injuries, traumatic; Hematoma, subdural; Hematoma, subdural, acute; Remission, spontaneous

\section{INTRODUCTION}

Acute subdural hematoma (ASDH) usually results from traumatic brain injury (TBI) and occurs in $12 \%$ to $30 \%$ of patients with severe head injury ${ }^{18)}$. A recent study suggested that the incidence has increased from $6.67 / 100,000$ to $14.7 / 100$,000 between 1993 and 2006 among US populations, and the cost to treat has increased $67 \%$ during that same period ${ }^{9)}$, which could present growing socioeconomic problems for patients with ASDH. It often results in neurologic deterioration and/or intracranial hypertension, requiring emergency decompression surgery for most patients ${ }^{4)}$. Patients with neurological deficits and signs of increased intracranial pressure (IICP) are considered for surgery, and they hold a high mortality rate, generally $40 \%$ to $70 \%$ in the literature depending on existing clinical factors such as the level of consciousness ${ }^{4,69)}$. Since ASDH with severe mass effect and neurologic symptoms almost always undergo immediate decompressive surgery, the observation of its natural clinical course is restricted to patients chosen for conservative treatment. There have been reported cases where the rapid resolution of ASDH showing neurological improvements with conservative treatment ${ }^{1-3,5,8,10,12,14,15,17,19-22)}$. Here, we report a case of ASDH with severe mass effect by hematoma subject to immediate surgery that showed gradual neurological progress after $8 \mathrm{hr}$ of admission and spontaneous resolution within 4 days after TBI. The possible proposed mechanism of the resolution of hematoma will also be discussed.

\section{CASE REPORT}

A 74-year-old male was admitted to our emergency room (ER) after slipping down in the bathroom. In 2009, he received cardiac valve replacement surgery for aortic valve stenosis and regurgitation and mitral valve regurgitation with atrial fibrillation and was on warfarin ever since. He was stuporous on admission with Glasgow Coma Scale (GCS) of E1V2M4. Initial brain computed tomography (CT) suggested a thick right frontotemporal ASDH shifting the right brain parenchyma to the left with subfalcine and uncal herniations (Fig. 1A). Immediate surgical intervention was considered as a first option of treatment. However, the family claimed that the patient held strong principles against any aggressive treatment with extensive general anesthesia and refused the surgery to honor his wishes. His respiration became progressively shallow but the family also refused endotracheal intubation.

He was admitted to the intensive care unit for close observation under medical treatment for ICP control. About $8 \mathrm{hr}$ later, during medical treatment, his consciousness became drowsy with GCS of E3V4M6, and the follow-up CT indicated slight signs of reduced amount of hematoma and partial restoration of the midline shift (Fig. 1B). His neurologic symptoms improved progressively and a brain CT taken approximately 4 days later showed a significant spontaneous reduction of hematoma with improved of midline shifting and herniation (Fig. 1C). Eventually, the patient developed a chronic SDH 

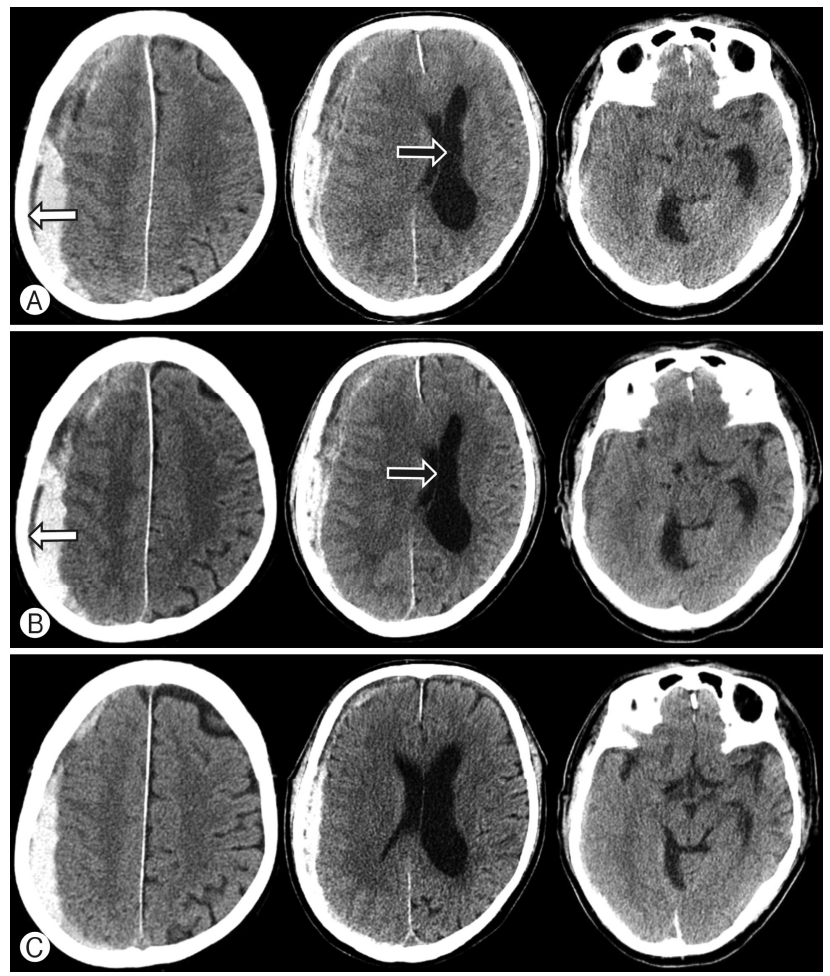

Fig. 1. (A) A $20 \mathrm{~mm}$-thick acute subdural hematoma at right frontotemporoparietal convexity with about $16 \mathrm{~mm}$ midline shiffing to the left (black arrow) on the initial computed tomography. A "low-density" band (white arrow) is visible between the skull and hematoma. (B) Approximately eight hours later, both the thickness of hematoma and midline shift reduced to $18 \mathrm{~mm}$ and $15 \mathrm{~mm}$ (black arrow) accordingly with neurologic improvements. A low-density band (white arrow) is visible. (C) The patient eventually gained consciousness after four days, and the computed tomography showed a significant resolution of the hematoma and parenchymal herniation.

$(\mathrm{CSDH})$ that was simply drained via burr-hole trephination (Fig. 2). He was discharged on the $20^{\text {th }}$ day of admission and able to return to his daily social activities with Karnofsky Performance Scale of 100 at about 3 months postdischarge. The follow-up brain CT showed a nearly complete resolution of SDH along the right cerebral convexity (Fig. 3).

\section{DISCUSSION}

It is generally accepted that ASDH with neurologic deficits and radiographically indicating severe brain injury calls for immediate surgical interventions such as decompressive craniectomy due to its fast lethal clinical course ${ }^{4)}$. However, there could be situations in the clinical field where surgical intervention is not performed for various reasons such as poor initial medical status and family wishes or a patient's will. Several case reports have shown patients whose ASDH resolved rapidly and spontaneously within hr to days with good clinical outcomes, as demonstrated by $\mathrm{CT}^{1-3,5,8,10,12,14,15,17,19-22)}$. We report

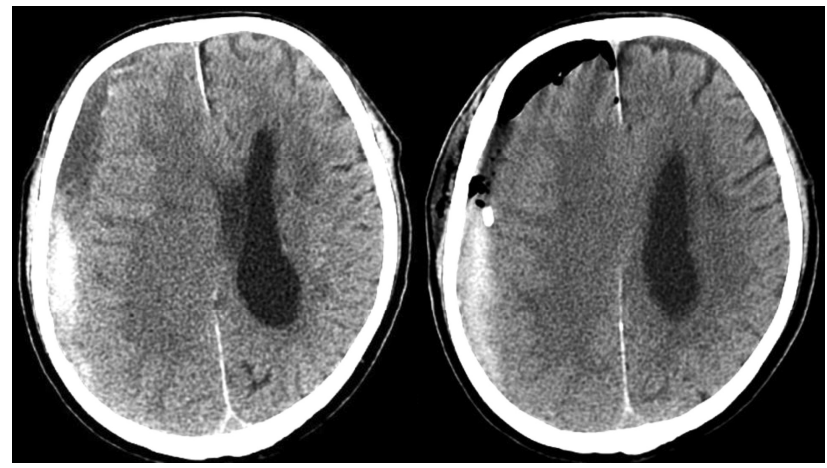

Fig. 2. The hematoma eventually transformed into the chronic phase (leff), which was drained via burr-hole trephination (right).

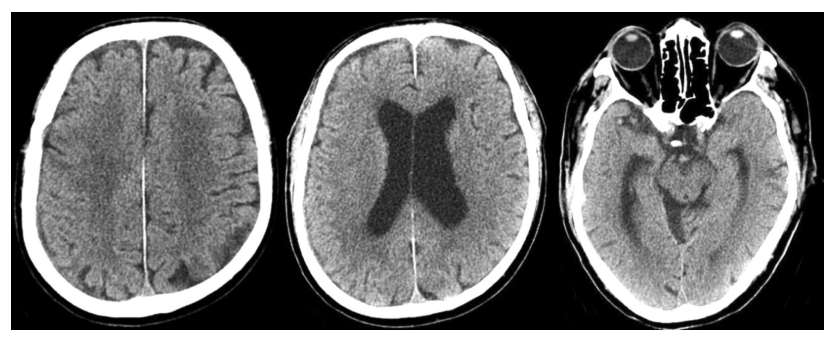

Fig. 3. A follow-up brain computed tomography taken after about 3 months of discharge revealed a nearly complete resolution of subdural hematoma.

a rare case of ASDH with a significant midline shift that resolved spontaneously under conservative treatment.

A simple ASDH with moderate thickness and visible "lowdensity band" between the hematoma and inner table of the skull on CT could be an indicator of the spontaneous resolution of hematoma, as suggested by other authors $2,8,12,14,17,19,21,22)$. Other factors such as brain atrophy and coagulopathy due to previous medical conditions could also be responsible for spontaneous resolution (Table 1). Such spontaneous resolution phenomena can be explained as a dilution of the hematoma by cerebrospinal fluid (CSF) that has leaked from a tear in the arachnoid membrane leading to a washout of blood products with increasing brain swelling and increased IICP ${ }^{16)}$. According to a review of adult cases on the spontaneous resolution of ASDH with mass effect, the most frequently mentioned factor to explain the disappearance of hematoma was the presence of a "low-density band" in CT (Table 1). Watanabe et al. ${ }^{21)}$ reviewed a case of an 88-year-old woman in a coma with ASDH who showed rapid resolution on CT and magnetic resonance imaging (MRI). Her consciousness steadily recovered to a GCS score of E2V4M5, and the follow-up brain CT revealed the spontaneous resolution of the hematoma and brain MRI showed a redistribution of hematoma to the supratentorial subdural space. Eventually, the patient developed CSDH 3 weeks later and a simple drainage was performed for evacuation. The author suggested that CSF had diluted the hematoma, which can be presumed from the "low-density band" on CT and that 
the presence of a wide subdural space due to brain atrophy from dementia might have caused the spontaneous resolution.

In our case, a "low-density" band was visible in the patient's CT taken at ER (Fig. 1A) and the follow-up CT images showed that the hematoma resolved around that band first (Fig. 1B, C). The laboratory evidence of coagulopathy with international normalized ratio prolongation might have played a role, since the patient was taking warfarin for his heart condition, eliciting liquefaction of the hematoma and may have promoted redis- tribution. In addition, the presence of brain atrophy due to his previous history of cerebral infarction and old age might have rendered some space to compensate for the acute IICP before brain herniation began, as a similar phenomenon suggested by other cases $2,5,12,17,20,21$ )

It has been suggested that the use of antiplatelet agents prior to head injury could increase the probability of rapid resolution. Fujimoto et al. ${ }^{7)}$ reviewed 366 patients in total with ASDH using univariate and multivariate logistic regression ana-

Table 1. Summary of case reports on spontaneous resolution of acute subdural hematoma with midline shift and its proposed mechanisms

\begin{tabular}{|c|c|c|c|c|c|c|c|c|c|}
\hline Author & Year & Sex & Age & $\mathrm{GCS}^{\S}$ & Coagulopathy $^{\ddagger}$ & $\begin{array}{l}\text { SDH thickness } \\
(\mathrm{mm})\end{array}$ & MLS & LDB & Proposed mechanism of resolution \\
\hline \multirow{4}{*}{$\begin{array}{l}\text { Niikawa } \\
\text { et al. }^{15)}\end{array}$} & \multirow[t]{4}{*}{1989} & M & 63 & 13 & NC & NC & Yes & $\mathrm{NC}$ & \multirow{4}{*}{$\begin{array}{l}\text { The dilution by CSF may be responsible for } \\
\text { rapid resolution of SDH via washing out or } \\
\text { redistribution. Acute brain swelling might } \\
\text { have triggered pressure-induced redistribution } \\
\text { of the ASDH. }\end{array}$} \\
\hline & & M & 16 & 3 & NC & NC & Yes & $\mathrm{NC}$ & \\
\hline & & $\mathrm{F}$ & 27 & 10 & NC & NC & Yes & $\mathrm{NC}$ & \\
\hline & & $M$ & 48 & 9 & NC & NC & Yes & NC & \\
\hline \multirow[t]{2}{*}{ Aoki $^{1)}$} & \multirow[t]{2}{*}{1990} & M & 22 & $N C^{*}$ & NC & NC & Yes & NC & \multirow{2}{*}{$\begin{array}{l}\text { An interhemispheric SDH shown in the follow- } \\
\text { up CT supports redistribution of the hematoma. }\end{array}$} \\
\hline & & $\mathrm{F}$ & 23 & $N C^{*}$ & NC & NC & Yes & NC & \\
\hline $\begin{array}{l}\text { Matsuyama } \\
\text { et al. }{ }^{14}\end{array}$ & 1997 & M & 18 & $15^{+}$ & NC & 15 & Yes & Yes & Dilution by CSF and redistribution \\
\hline $\begin{array}{l}\text { Cohen } \\
\text { et al. }\end{array}$ & 1998 & M & 27 & 7 & NC & NC & Yes & NC & $\begin{array}{l}\text { Brain atrophy due to } \mathrm{HIV}-1 \text { encephalopathy } \\
\text { promoted CSF dilution and washout, thus } \\
\text { facilitating redistribution. }\end{array}$ \\
\hline $\operatorname{Imai}^{8)}$ & 2003 & $\mathrm{~F}$ & 83 & 6 & $\mathrm{NC}$ & 15 & Yes & Yes & $\begin{array}{l}\text { The low-density band suggests CSF dilution } \\
\text { and wash-out theory. }\end{array}$ \\
\hline $\begin{array}{l}\text { Berker } \\
\text { et al. }\end{array}$ & 2003 & $M$ & 57 & 7 & $\mathrm{NC}$ & NC & Yes & NC & $\begin{array}{l}\text { Skull fracture causes tearing of the arachnoid, } \\
\text { and washing out by CSF, promoting } \\
\text { redistribution of the hematoma. }\end{array}$ \\
\hline \multirow{2}{*}{$\begin{array}{l}\text { Sato } \\
\text { et al. }{ }^{17)}\end{array}$} & \multirow[t]{2}{*}{2005} & $\mathrm{~F}$ & 92 & 7 & NC & NC & Yes & Yes & \multirow{2}{*}{$\begin{array}{l}\text { Brain atrophy due to aging and CSF dilution } \\
\text { indicated by LDB could result in rapid } \\
\text { spontaneous resolution of the hematoma. }\end{array}$} \\
\hline & & $M$ & 88 & 10 & $\mathrm{NC}$ & $\mathrm{NC}$ & Yes & Yes & \\
\hline $\begin{array}{l}\text { Kapsalaki } \\
\text { et al. }{ }^{10)}\end{array}$ & 2007 & $M$ & 29 & 8 & Yes & 18 & Yes & No & $\begin{array}{l}\text { Increased ICP as a driving force responsible } \\
\text { for spontaneous resolution of the } \\
\text { hematoma. CSF washout and redistribution. } \\
\text { Examined only young patients. }\end{array}$ \\
\hline $\begin{array}{l}\text { Wen } \\
\text { et el. }^{22)}\end{array}$ & 2009 & M & 22 & 11 & NC & NC & Yes & Yes & $\begin{array}{l}\text { CSF participation and LDB caused dilution } \\
\text { and redistribution. }\end{array}$ \\
\hline $\begin{array}{l}\text { Lee } \\
\text { et al. }{ }^{12)}\end{array}$ & 2009 & M & 61 & 4 & NC & 25.9 & Yes & Yes & $\begin{array}{l}\text { Dilution by CSF and redistribution in patients } \\
\text { with brain atrophy. }\end{array}$ \\
\hline $\begin{array}{l}\text { Watanabe } \\
\text { et al. }\end{array}$ & 2010 & $F$ & 88 & 4 & NC & NC & Yes & Yes & $\begin{array}{l}\text { Participation of the CSF (LDB in CT) and } \\
\text { presence of a wide subdural space due to } \\
\text { brain atrophy }\end{array}$ \\
\hline Shin et al. ${ }^{19)}$ & 2013 & F & 40 & 6 & NC & 10 & Yes & Yes & Dilution of ASDH caused by CSF flow. \\
\hline Bae et al. ${ }^{2)}$ & 2014 & M & 67 & 5 & Yes & 25 & Yes & Yes & $\begin{array}{l}\text { Dilution by CSF and redistribution of the } \\
\text { hematoma in patients with brain atrophy } \\
\text { and coagulopathy due to liver cirrhosis. }\end{array}$ \\
\hline $\begin{array}{l}\text { Towers and } \\
\text { Kurtom }^{20)}\end{array}$ & 2014 & $F$ & 84 & 11 & Yes & 16 & Yes & No & $\begin{array}{l}\text { Multiple factors. Dilution of the hematoma } \\
\text { with CSF and redistribution, coagulopathy } \\
\text { and significant brain atrophy. }\end{array}$ \\
\hline
\end{tabular}

M: male; F: female; GCS: Glasgow Coma Scale; NC: not commented; SDH: subdural hematoma; MLS: midline shift; LDB: low-density band; CSF: cerebrospinal fluid; CT: computed tomography; HIV-1: human immunodeficiency virus 1; ICP: intracranial pressure.

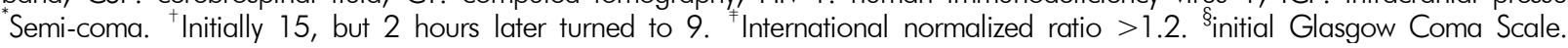


lyses to identify predictors for rapid spontaneous resolution. In his study, the pre-hospital use of antiplatelet agents and the presence of a low-density band between the hematoma and inner skull bone on initial CT could be associated with liquefaction of the hematoma, thus encouraging rapid spontaneous resolution by facilitating redistribution with brain swelling. Other studies also supported this hypothesis, although brain atrophy instead of brain swelling is suggested as a main contributor in the process of dilution and redistribution ${ }^{2,20)}$.

Other hypotheses deal with a redistribution of hematoma and its products, caused by either brain swelling leading to IICP or further bleeding from the site ${ }^{11,13,15)}$. In 1989, Niikawa et al. ${ }^{15)}$ reported that the dilution by CSF may be responsible for the rapid resolution of SDH via washing out or redistribution, and acute brain swelling might have triggered the pressure-induced redistribution of the ASDH. Another possible mechanism of the resolution could be a redistribution of the hematoma into other subdural or extracranial spaces through a fracture site of the skulli). Berker et al. ${ }^{3)}$ explained that such a process, in turn, could have triggered tears in the arachnoid membrane, thus washing out the hematoma by CSF. However, our case did not present with a definite skull fracture site or hemorrhages in other subdural spaces, making this less likely.

\section{CONCLUSION}

Although immediate surgical intervention is generally accepted as a golden standard for the treatment of ASDH with severe neurological progress, neurosurgeons must be aware that hematoma can resolve spontaneously in rare circumstances. When patients hold a high operative risk of taking anticoagulants with a visible "low-density band" in the brain CT and are very old, their guardians must be informed of the potential for spontaneous resolution. However, surgical decompression should remain the treatment of choice in ASDH with neurologic deficits and severe midline shift.

\section{CONFLICTS OF INTEREST}

No potential conflict of interest relevant to this article was reported.

\section{REFERENCES}

1. Aoki N: Acute subdural haematoma with rapid resolution. Acta Neurochir (Wien) 103:76-78, 1990

2. Bae HJ, Lee SB, Yoo DS, Huh PW, Lee TG, Cho KS: Rapid spontaneous resolution of acute subdural hematoma in a patient with liver cirrhosis. Korean J Neurotrauma 10:134-136, 2014

3. Berker M, Gulsen S, Ozcan OE: Ultra rapid spontaneous resolution of acute posttraumatic subdural hematomas in patient with temporal linear fracture. Acta Neurochir (Wien) 145:715-717, 2003

4. Bullock MR, Chesnut R, Ghajar J, Gordon D, Hartl R, Newell
DW, et al.: Surgical management of acute subdural hematomas. Neurosurgery 58:S16-S24, 2006

5. Cohen JE, Eger K, Montero A, Israel Z: Rapid spontaneous resolution of acute subdural hematoma and HIV related cerebral atrophy: case report. Surg Neurol 50:241-244, 1998

6. Feliciano CE, De Jesús O: Conservative management outcomes of traumatic acute subdural hematomas. P R Health Sci J 27:220223, 2008

7. Fujimoto K, Otsuka T, Yoshizato K, Kuratsu J: Predictors of rapid spontaneous resolution of acute subdural hematoma. Clin Neurol Neurosurg 118:94-97, 2014

8. Imai K: Rapid spontaneous resolution of signs of intracranial herniation due to subdural hematoma--case report. Neurol Med Chir (Tokyo) 43:125-129, 2003

9. Kalanithi P, Schubert RD, Lad SP, Harris OA, Boakye M: Hospital costs, incidence, and inhospital mortality rates of traumatic subdural hematoma in the United States. J Neurosurg 115:10131018, 2011

10. Kapsalaki EZ, Machinis TG, Robinson JS, 3rd, Newman B, Grigorian AA, Fountas KN: Spontaneous resolution of acute cranial subdural hematomas. Clin Neurol Neurosurg 109:287-291, 2007

11. Kuroiwa T, Tanabe H, Takatsuka H, Arai M, Sakai N, Nagasawa $\mathrm{S}$, et al.: Rapid spontaneous resolution of acute extradural and subdural hematomas. Case report. J Neurosurg 78:126-128, 1993

12. Lee CH, Kang DH, Hwang SH, Park IS, Jung JM, Han JW: Spontaneous rapid reduction of a large acute subdural hematoma. J Korean Med Sci 24:1224-1226, 2009

13. Makiyama Y, Katayama Y, Tsubokawa T: Rapid, spontaneous disappearance of acute subdural hematoma. Neurosurgery 21: 429, 1987

14. Matsuyama T, Shimomura T, Okumura Y, Sakaki T: Rapid resolution of symptomatic acute subdural hematoma: case report. Surg Neurol 48:193-196, 1997

15. Niikawa S, Sugimoto S, Hattori T, Ohkuma A, Kimura T, Shinoda J, et al.: Rapid resolution of acute subdural hematoma-report of four cases. Neurol Med Chir (Tokyo) 29:820-824, 1989

16. Polman CH, Gijsbers CJ, Heimans JJ, Ponssen H, Valk J: Rapid spontaneous resolution of an acute subdural hematoma. Neurosurgery 19:446-448, 1986

17. Sato M, Nakano M, Sasanuma J, Asari J, Watanabe K: Rapid resolution of traumatic acute subdural haematoma in the elderly. Br J Neurosurg 19:58-61, 2005

18. Servadei F: Prognostic factors in severely head injured adult patients with acute subdural haematoma's. Acta Neurochir (Wien) 139:279-285, 1997

19. Shin DW, Choi CY, Lee CH: Spontaneously rapid resolution of acute subdural hemorrhage with severe midline shift. J Korean Neurosurg Soc 54:431-433, 2013

20. Towers WS, Kurtom KH: Spontaneous resolution of large acute subdural hematoma and the value of neurological exam in conservative management of high risk patients. Clin Neurol Neurosurg 118:98-100, 2014

21. Watanabe A, Omata T, Kinouchi H: Rapid reduction of acute subdural hematoma and redistribution of hematoma: case report. Neurol Med Chir (Tokyo) 50:924-927, 2010

22. Wen L, Liu WG, Ma L, Zhan RY, Li G, Yang XF: Spontaneous rapid resolution of acute subdural hematoma after head trauma: is it truly rare? Case report and relevant review of the literature. Ir J Med Sci 178:367-371, 2009 